\title{
Ortografía y fonética en la Aurora de Chile*
}

\author{
Sonia Almau Almau** \\ Universidad de Zaragoza, España
}

\begin{abstract}
Resumen
En este trabajo se analizan los aspectos ortográficos y fonéticos más significativos del periódico "ministerial y político" la Aurora de Chile, dirigido por Camilo Henríquez y redactado por numerosos colaboradores, que apareció semanalmente en 1812 y 1813 . Dicho periódico posee un indudable valor documental no solo por ser el primer impreso relevante de Chile, sino por tratarse de un corpus amplio, compuesto por noticias nacionales e internacionales de diversa índole, que refleja perfectamente las preocupaciones ideológicas del movimiento independentista.
\end{abstract}

Palabras clave: español americano, Aurora de Chile, ortografía, fonética.

* Del Proyecto FFI2008-02718/FILO, MICINN.

** Para correspondencia, dirigirse a: Sonia Almau Almau (salmau@unizar.es), Departamento de Lingüística General e Hispánica, Facultad de Filosofía y Letras, Universidad de Zaragoza, Pedro Cerbuna 12, 50009 Zaragoza, España. 


\title{
Orthography and phonetics in the Aurora DE Chile
}

\begin{abstract}
This paper analyses the most significant orthographic and phonetic aspects of Aurora de Chile, a ministerial and political newspaper published weekly during 1812-1813, which was directed by Camilo Henríquez and written by many contributors. This newspaper has an enormous documentary value, not only because it is the first relevant newspaper in Chile, but also because it constitutes a large corpus, which is made up of national and international news of various kinds, and which clearly reflects the independence movement ideological concerns.
\end{abstract}

Key words: American Spanish, Aurora de Chile, orthography, phonetic.

Recibido: 30/03/10. Aceptado: 25/04/10.

\section{NOTA INTRODUCTORIA}

La Aurora de Chile 1 , "periódico ministerial y político", como se autodenomina en la cabecera de sus números, es un documento de indudable valor no solo como muestra impresa de la lengua española que a comienzos del siglo XIX se hablaba en el sur del continente americano, sino también como testimonio de un período convulso en el que la prensa, difundida por la necesidad de propaganda política, se erigía como uno de los más importantes medios de comunicación de la época, en cuanto a que en él se recogían noticias nacionales e internacionales de índole diversa. Pero no solamente de datos presuntamente objetivos se nutrían los periódicos de esta centuria, entre ellos la Aurora, sino que daban cabida a numerosos artículos de opinión y

Los ejemplos que se extraen del periódico serán indicados en este trabajo con la numeración entre paréntesis de la página correspondiente. La mayoría de las alusiones pertenecen al año de 1812 y son solo algunos casos puntuales, que aparecerán debidamente marcados, los que se han tomado de los números de 1813 . Se ha utilizado la abreviatura $p$ para indicar que se trata del prospecto. 
editoriales, auténticos manifiestos que perfilan el discurrir de los principales cambios políticos e ideológicos del momento.

Cada jueves, entre los años 1812 y 1813, un ejemplar de la Aurora chilena "veía la luz", por seguir con la terminología que utilizaron los redactores del periódico - como buenos representantes de los valores de la Ilustración-para plasmar la idea del "amanecer político y cultural" que subyace en numerosos ejemplares de un periódico "cuio título anuncia frutos más sazonados, y días más brillantes, prósperos, y serenos", como señala en el prospecto el director de la publicación, fray Camilo Henríquez, quien firma en otras ocasiones con seudónimos como Cayo Horacio y Julio Público. Junto a él había importantes colaboradores comprometidos política e ideológicamente con la independencia de Chile, figuras como la del abogado y político chilenoargentino Bernardo de Vera y Pintado, el militar guatemalteco-chileno Antonio José de Irisarri o el educador Manuel de Salas.

El discurso de estos próceres de la Independencia es de un nivel culto y en muchos casos de estilo grandilocuente y exaltado, aunque no es el objetivo de este trabajo analizar el tono de unas palabras que anuncian una clara ruptura política y, en menor medida, cultural, sino el de estudiar las huellas manifiestas que ese cambio deja en un español configurado por dos grandes fuerzas antagónicas: tradición e innovación. En concreto, se van a analizar los rasgos más significativos del periódico chileno en materia de ortografía y fonética. Para ello se va a tener siempre presente la idea de que antes de la Aurora no había habido en Chile una tradición impresa consolidada, lo que supone la existencia de una proximidad mayor a los usos de la escritura manual y, por ende, de una normalización ortográfica todavía en ciernes.

\section{ORTOGRAFÍA}

El análisis ortográfico del corpus periodístico chileno ofrece importantes pistas a la hora de conocer los usos grafemáticos de la época y tangencialmente el nivel cultural y el tipo de instrucción de su redactor y colaboradores. A grandes rasgos, se puede decir que se trata de un corpus bastante tradicional en lo que a materia ortográfica se refiere, lo que se observa en la aparición de rasgos arcaicos tales como el mantenimiento de grafías cultistas que se utilizan, en no pocos casos, con la pretensión de ajustarse a la etimología de las palabras. Sin embargo, ese afán purista por mantener los usos gráficos tradicionales contrasta también con la existencia de abundantes errores ortográficos desde el punto de vista actual, que tienen su entronque en la evolución histórica y que la Academia venía ya señalando desde 1726 en el 
prólogo del Diccionario de Autoridades. Sin embargo, la norma ortográfica creada en la Península tardará en establecerse en la práctica escolar de España $\mathrm{y}$, sobre todo, de los territorios ultramarinos.

\subsection{CULTISMO ORTOGRÁFICO Y TRADICIÓN ETIMOLOGIZANTE}

El prurito cultista de los creadores del periódico se observa, por ejemplo, en la utilización generalizada de la $q$ latinizante para representar la $/ \mathrm{k} /$, una grafía que seguirá apareciendo hasta la primera mitad del siglo XIX no solo en textos americanos sino también en escritos ministeriales españoles, como señala Frago Gracia (2007: 152-153)², a pesar de que ya había sido eliminada por la Academia en 1775, una norma ortográfica que tardará en regularizarse incluso en la misma obra académica, pues hasta la edición del diccionario de 1803 se dice en la entrada de dicha grafía: "Síguele siempre una $u$, que las más veces se liquida perdiendo enteramente el sonido: como en querer, y algunas veces se pronuncia, aunque suavemente, como en qual, quando, etc."'. Habrá que esperar a la edición de 1817 para poder leer en la entrada de $q$ una explicación coherente con la regla formulada cuarenta años antes: "En castellano, a imitación del latín, nunca se usa la $q$ sin poner después de ella la $u$, la cual se elide y suprime en la pronunciación y por esta causa se remitirán a la $c$ todas las voces en que suene o se pronuncie esta vocal" (NTLLE).

En la Aurora son numerosísimas las formas que aparecen con $q$ inicial, tal como quanto/a/os/as $(14,78,61,78)$, quan (2) qual/es $(4,64)$, quando $(15,66)$ y la expresión "de quando en quando" (188), qualquier/a (76, $140)$, así como los numerales cardinales quatro $(2 \mathrm{p}, 42)$ quarenta $(60,79)$, quatrocientos/as $(34,152)$, y el ordinal quarta (137). Además de estas

2 El problema básico que se plantea con esta grafía y con las que veremos a continuación es, como señala el Autoridades, la existencia de varias letras para representar sonidos ya indistintos desde hace varios siglos: "porque aun dado el caso de que todos hablen y pronuncien de un mismo modo y sin la menor diferencia, no es dable que en muchíssimas palabras se pronuncien tan distinta y separadamente las mismas letras de que se componen que se conozca por sola la pronunciación quales son y de que modo se deben escribir (...) hasta ahora ninguno, por más vivo que tenga el oído, ha podido distinguir por la mera pronunciación de estas voces cuenta, qüestión, cueva, eloqüencia, freqüencia, pescuezo, quanto, qual, cuajo, quales son con $C$ y quales con $Q \ldots$..." (LXVIII).

3 Obsérvese el lenguaje gramaticalmente arcaico utilizado por la Academia en esta cita con el uso de "se liquida", así como tampoco es objetiva la referencia fonética a la pronunciación "suave" de la /k/ en qual. 
formas, en el periódico chileno tienen amplio uso grafías como quartel/es $(25,112)$, quadro, quadra $(73,108)$, esquadrón/es, esquadra, esquadrilla $(38,127,108)$, qualidadles $(125,19)$, adequada, adequadamente $(21,189)$. Casos más aislados son palabras como ebaqué 'evacué' (40), quasi (132), iniquo, iniquamente $(131,72)$, quota $(177)$, antiquados $(1 \mathrm{p})$, quaderno (46), equador (121), equestre (136), desquartizaron (135), sequaces (92), questores $(78)^{4}$.

En ocasiones, se observa la aparición de la diéresis en palabras escritas con $q u$ del tipo freqüente, freqüencia $(1 \mathrm{p}, 39)$, qüestión/es $(43,44)$, conseqüencia/s $(25,68)$, obliqüos (66), iniqüo (22). Sin embargo, la colocación de este signo diacrítico es arbitraria y ya no se utiliza para "apartar dos vocales que se pueden juntar en una sýlaba y notar que se deben pronunciar distinta y separadamente" (LXIII), tal y como recomendaba Autoridades, puesto que el impreso está surcado de dobletes, palabras que aparecen frecuentemente tanto con diéresis como sin ella: eloqüencia, eloqüentes $(53,18)$ / eloquencia, eloquente (80,77), delinqüentes (32) / delinquente (88), cinqüenta (158) / cinquenta (79).

El afán purista de escritores y redactores se manifiesta asimismo en el mantenimiento de ciertas grafías compuestas de signo etimologizante del tipo ch en Christóbal (24), christianos (35), machiabélica (72), architectura (140) y monárchico (174), y th en Mathías (24), ether (73), theorías (80), Theodoro (84), theólogos (174) y pathológica (19, en 1813). Formas cultistas son también sumtuosos y sumtuosidad (22, en 1813) al conservar la $m$ etimológica, así como aquellas que contienen la misma grafía duplicada por latinismo ortográfico, como se observa en annual (110) y Excellentísimo (17) o el topónimo Asumpción (185), con mantenimiento del grupo mp.

De forma arbitraria se siguen colocando las grafías $c-z$ en esta época, con lo que es difícil establecer generalizaciones sobre su uso. Sin embargo, si algo se puede destacar en este punto es la aparición en el texto chileno de la forma casi exclusiva zelo ${ }^{5}$, con el mantenimiento de la grafía etimológica $z$, que propuso el diccionario de Autoridades (LXXIII) -aunque era un uso que venía practicándose desde siglos antes-, y de la que pueden rastrearse abundantes ejemplos en la Aurora $(15,21,45 \ldots)$, así como de palabras pertenecientes a su misma familia del tipo rezelos (1), zelosos (36), zelosísima (50), habituales en textos del XVIII y del XIX. La Academia asimismo señaló en su Orthographía (1741?): "Las sýlabas ce, ci, se deben escribir siempre

De todos los ejemplos aportados, solo la forma ebaqué no tiene $q$ en su étimo latino. Son escasas las formas con c: recelos $(1 \mathrm{p}, 186)$, recela $(132)$, celosos $(4$, en 1813). 
con $c$, v. g. cenar, ciento y la $z$ solo se debe escribir en aquellas pocas voces que en su origen la tienen, como zelo, cizaña ${ }^{6}$. La razón es, porque, siendo la misma la pronunciación, el uso de nuestra lengua prefiere la $c$ a la $z$ " (146, $147)^{7}$. En el periódico chileno, sin embargo, es frecuente la aparición de la $z$ ante las vocales palatales $e, i$ en términos como juezes y pazes $(102,50)^{8}$, en numerosas formas verbales, quizás por extensión a partir del infinitivo correspondiente, del tipo de goze (87), organize (45), escandalizen (161), abrazen (48), erizen (128), trazé (157), comenzemos (70), eternize (144), en los sustantivos deverbales como alcanzes (89) y en las formas derivadas del tipo cabezillas (120).

También de fuerte componente tradicionalista es el uso de la y, una grafía que se introdujo con los helenismos del latín clásico y consiguió extenderse a las voces patrimoniales, adquiriendo un gran simbolismo que mantuvo a lo largo de la historia escrituraria y que hizo de ella una de las grafías cultistas que más pervivencia ha tenido, no solo en América, sino también en España, como muestra Frago Gracia (2008: 42-43) valiéndose del ejemplo de dos ilustres aragoneses:

el mismo Goya se servía de esta grafía, y no era rara en su tiempo la superpuntuación arcaizante de la letra pitagórica (...) Ni es raro, dado el simbolismo que a esta letra acompañó durante siglos, que en el Acta

6 Parece un desliz de la Academia la inclusión de este segundo ejemplo con la grafía $c$, puesto que zizaña -forma que recoge Covarrubias ((1611) 1979)- es el único registro que aparece en el diccionario académico hasta 1869, cuando se incluye ya la forma actual (NTLLE). Sin embargo, Terreros opta por señalar: "Z, antes de e, i. V. en C", con lo que únicamente aparece el registro cizaña. Corominas (1954) indica que procede del latín tardío zizanĭa,

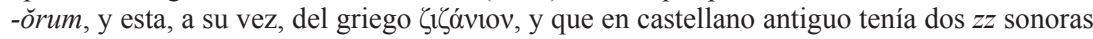
que aún hoy se conservan en judeoespañol.

7 A pesar de señalar en esta ocasión la igual pronunciación de ambas grafías, la Academia, como señala Rosenblat (1971: 78), no parece muy convencida de la equivalencia fónica de ce y ze en la Ortografía de 1815, donde se explica la articulación de la $z$ como la aproximación de la parte anterior de la lengua a los dientes "no tan pegada como para la $c$, sino de manera que quede paso para que el aliento o espíritu, adelgazado o con fuerza, salga con una especie de zumbido" $(58,59)$. No es de extrañar, por tanto, que hubiese gramáticos en el siglo XIX que se empeñaran en imponer la distinción, como don Mariano José Sicilia, profesor de Filosofía moral y de derecho que "sostuvo tenazmente que se pronunciaban de manera distinta celoso, de celo ("celoso cumplidor de sus deberes") y zeloso, de zelos ("un novio zeloso")" (Rosenblat 1971: 78).

8 A pesar de lo que recomendaba la Academia en su Orthographía (1741?: 147): "Quando los nombres en número singular acaban en $z$ y en el plural se terminan en ces, esta sýlaba se escribe con $c$, como felices de feliz, veces de vez y lo mismo sucede en los derivados y así felicidad de feliz, capacidad de capaz". 
oficial del nombramiento de Ramón y Cajal como Director del Instituto Cajal, de 12 de noviembre de 1920, se pusiera Ynstituto.

En la Aurora chilena aparece aún esta grafía a comienzos de palabra, sobre todo en nombres propios como Ydalgo (apellido) (76), Ygnacio (76) o Ysidoro $(163)^{9}$, o, ya en casos más aislados, en palabras concretas como hymnos / ymnos $(89,90)$, un uso ortográfico que perduró hasta mediados del siglo XIX en textos muy diversos. Más frecuente es la aparición de esta grafía como segundo elemento constitutivo de un diptongo decreciente en términos del cariz de paysano (83), pleytos (84), ayre (2p), traydoramente (30), cuydado (32), deleyta (166), bayle (192), distraygan (186), en nombres de persona como Jayme (85) e, incluso, en topónimos tan conocidos como Hayti (44) y Buenos Ayres (124). No obstante, las formas con $y$ que cuentan con mayor aparición son reyno $(2 \mathrm{p}, 17)$ y todas las pertenecientes a su familia: reyna (16), virreynato (136) y reynantes $(172)^{10}$, por ejemplo, a pesar de que ya Autoridades (LXXXIV) dijo explícitamente: "es error notorio usar de la $y$ escribiendo ayre, reyno, toysón, buytre, debiendo escribirse con $i$ latina, y la razón es porque no hiere a otra vocal" ${ }^{11}$ (para mui, v. n. 12).

Esta $y$ también puede aparecer formando parte de un hiato, como se registra con frecuencia en el vocablo paýs (138) y en formas verbales del tipo oyr (183), veýan (139) y leýdo (185), así como en otros testimonios más aislados: raýzes (186). Como resabio cultista, así mismo, se puede observar la presencia de esta grafía en el interior de vocablos como systema (1,3p), Hydrodinámica (80), hydrógeno (20), ínclytas (141), hypocresía (162) y polýgono (179). Probablemente a ese carácter cultista de la $y$ se deba también el hecho de que en algunos titulares escritos en mayúsculas se utilice únicamente dicha grafía: "Por la mañana corryó entre los cyudadanos

9 La explicación reside, de nuevo, en el fuerte carácter conservador que poseen los nombres propios, como comenta Rosenblat $(1971: 71,72)$ en su capítulo “¿Yrigoyen o Irigoyen?”: "Los nombres propios son más reacios que las voces corrientes a la acomodación ortográfica (en el siglo XIX todavía se escribía Buenos Ayres o Maracaybo). Y los apellidos aún mucho más. En parte porque ha surgido en los últimos tiempos el orgullo del apellido, y se hace cuestión de honor mantenerlo en su supuesta pureza ancestral".

10 Sin embargo, aparece también la palabra reino con la grafía actual (48), lo que puede deberse a que la palabra está inserta en una carta de Espoz y Mina, guerrillero español quizás perteneciente a una tradición escrituraria más innovadora.

11 Los propios académicos obviaron esta recomendación en otras obras, como ponen de manifiesto las siguientes palabras: "Quando la $y$ que se sigue a otra vocal se pronuncia unida con ella, formando casi diptongo, se escribe con $y$ griega en la mayor parte de las voces, como ayre, donayre, muy, ley, reyno" (Orthographía 1741?: 173). 
de Norte Améryca resydentes en esta capytal la octava sygvyente, que se presentó al públyco ympresa" (92).

También se puede rastrear en el periódico la aparición de $i$ latina en lugar de la griega al final de palabra en vocablos tan usuales como los adverbios mui $(2,14)$ y hoi $(74)^{12}$, las formas verbales hai (79), voi (139) $)^{13}$, estoi (71), y los términos rei (70) y Paraguai (102), si bien se constatan también las formas hoy (86) y Paraguay (102) ${ }^{14}$. Además, la $i$ no solo representa el fonema vocálico, sino también el fonema palatal $/ \mathrm{y} /$ en el relativo cuio, cuia $(2 \mathrm{p}, 4),-$ que aparece en la misma página con $y$ griega: cuya (4)-, y en las formas verbales influien (12) y haian (99), uso consonántico de la $i$ propugnado por Nebrija en su gramática y en su ortografía, que anteriormente ya había sido frecuente en el castellano escrito y que continuaría siéndolo hasta enlazar con la ortografía de don Andrés Bello. En resumen, la continua aparición de vocablos escritos con una y otra grafía $(i / y)$ es una muestra destacable de la inestabilidad ortográfica que en este punto se daba todavía a comienzos del siglo XIX, así como de un indudable apego a ciertos usos escriturarios en muchos casos.

\subsection{OtRAS CUESTIONES}

Fue tendencia muy extendida desde antiguo la representación del fonema $/ \mathrm{g} / \mathrm{a}$ través del dígrafo $g u$ ante /e, i/ y de $g$ ante /a, o, $\mathrm{u}$ /, aunque desde el principio se pueden rastrear ejemplos que no se ajustan a esta distribución, como ya señalara Frago Gracia (1993: 297, 298) al estudiar documentación andaluza del siglo XVI, concretamente las Ordenanzas de Carmona de principios de esta centuria:

menos puede asombrar que en OCC, corpus no literario, tanto se lea desgarretar como espigua, siguan y pague-pagen. Se verifica en este

12 Mui es la forma que aparece en Autoridades y Terreros, mientras que el adverbio con la grafía usada actualmente se empieza a registrar a partir de 1780. Menos sistemática es la escritura del vocablo hoy: en Terreros está recogida como oi y en Autoridades con la forma oy (y precisa sobre la $h$ : "Viene del latino hodie, por cuya razón parece se debía escribir con $h$, pero el uso común lo escribe sin ella").

13 Esta misma forma se encuentra también en el Manifiesto que hace a los pueblos de Chile José Miguel de Carrera (1818: 38).

14 No obstante, la $i$ latina en ningún caso se ha utilizado para representar la conjunción copulativa, algo que sí se encuentra en el Manifiesto de Carrera (1818: 34), concretamente en un conector oracional (en mayúscula). 
punto una fluctuación grafémica en la que las formas señaladas (pagen 'paguen', siguan 'sigan', desgarretar 'desjarretar', etc.) no dejan de constituir excepciones a usos muy difundidos, aunque la conculcación pueda ser predominante en algún escrito suelto (...) y aunque su presencia esporádica sea fácil de rastrear en infinidad de documentos.

En el corpus periodístico chileno también aparecen claras desviaciones de dicha tendencia como jugete $(20)$, gerra, gerrero $(150,126)$, persigió $(187)$ y sanginarios, sanginaria $(147,177)$, de un lado, y urguían 'urgían' (146) y aguosto 'agosto' (4), de otro, lo que pone de manifiesto la inestabilidad grafemática en este aspecto todavía a principios del ochocientos ${ }^{15}$.

Asimismo se observa confusión gráfica a la hora de representar la $/ \mathrm{h} /$ americana (diferente de la /x/ norteña peninsular), ya que existían tres letras para representar un único sonido ${ }^{16}$, y no será hasta 1815 cuando la Academia deseche la $x$ en favor de la $j$. Hasta ese momento, la clave para diferenciar la colocación de una grafía u otra residía, para la institución académica, en la etimología de la palabra ${ }^{17}$. En este sentido, Autoridades (LXXIV) señala: "el medio para no confundirlas $[j, x]$ es atender a las raíces de las palabras, porque si tienen $x$, como en vexación, relaxación, execución, exemplo, exido, vexiga, perplexo, enxundia, no hai motivo para desfigurarlas escribiéndolas con $j$ ". En la Aurora aparecen escritos del mismo modo alguno de estos vocablos: exemplo (en nota, 3$)$, vexaciones, vexamen $(135,48)$, perplexidad (125), relaxación $(35)$.

15 En el Manifiesto de Carrera (1818: 18) aparece la forma segían 'seguían'. Estos casos podrían interpretarse como faltas ortográficas si quienes las cometieron se hubieran formado con la ortografía de la Academia, lo que no es nada seguro; de ahí que haya que considerarlas simplemente fluctuaciones grafemáticas que perviven hasta que se hace sistemática la enseñanza de la reglas académicas.

16 "Hasta ahora ninguno, por más vivo que tenga el oído, ha podido distinguir por la mera pronunciación de estas voces (...) agente, consejero, aloxa, ximia, xabón, enxambre, paja, page, quales son con $G$ y quales con $J$ y quales con $X$ " (Autoridades: LXVIII).

${ }^{17}$ La imposición de esta $x$ con criterio etimológico (pronunciada como $/ \mathrm{h} /$ ) coincidió con la recuperación de la $x$ en latinismos como examen, extraño (con la pronunciación / ks/o /gs/), por lo que había una grafía que representaba dos sonidos diferentes. En 1741-dato que aporta Rosenblat (1971: 54)- la Academia intentó resolver el enredo colocando en los cultismos con $x$ un acento circunflejo en la vocal siguiente a dicha $x$, lo que puede justificarse con la aparición en la edición de 1780 de formas como exâcto, exâmen, etc. (NTLLE). Fue en la $8^{\text {a }}$ edición de la Ortografía (1815) y la $5^{\text {a }}$ del Diccionario (1817) donde la Academia adoptó el criterio actual, es decir, reservar la $x$ para los latinismos en los que se debía pronunciar $/ \mathrm{ks} /$ y la $j$ para los casos en los que se pronunciaba /h/. No obstante, en la Aurora chilena todavía aparece - de forma muy aislada- alguna palabra con acento circunflejo en la vocal siguiente a la $x$ latina: exôneramos (27), exîstencia (28) auxîliar (47), reflexîones (48). 
Significativo es el hecho de que en el periódico chileno se continúe utilizando todavía la grafía medieval de justificación etimológica en verbos tan frecuentes como fixen (3), exercer (2) y sus derivados exército, exercicio $(14,1)$, formas verbales en pretérito perfecto simple de las que son una muestra dixo (15), traxo (79), bendixo (43), produxeron (54), induxo (47), o palabras como luxo (53), influxo (45), xarcias (33), prolixa (48), paradoxa (123), próximo 'prójimo' (166). Además, esta grafía aparece también en forma tradicional con antropónimos del tipo Xara (45), Mexía (146), Ximénez (97) Xavier (61) y topónimos como México (135), Guadalaxara (134), Oaxaca (135), Guanaxuato (135), Texas (135), Xaraquemada (88), Alpuxarras (38) y Xerez (42), costumbre escrituraria esta última que en algunas de tales voces se impondrá hasta hoy en tierras americanas debido al carácter conservador que poseen los nombres propios ${ }^{18}$.

Sin embargo, ejemplos como los anteriores no sirven para demostrar que la perspectiva etimológica de la Academia fuera efectiva entre los redactores del periódico, en primer lugar, porque el desconocimiento que de ella tuvieron los escritores de la época es más que probable y, en segundo, porque la argumentación de los académicos es en muchas ocasiones confusa, como muestra la siguiente cita:

También se debe usar de la $x$, y no de la $j$, quando las voces tienen en su origen \, como caxa, dexar, xabón, xugo, xeme, que salen de cap $\int$,

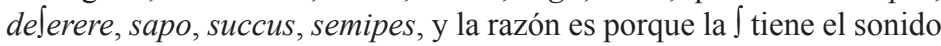
mui parecido al de la $x$, y como los españoles tomamos de los árabes la pronunciación gutural y estos pronuncian las $\iint \operatorname{como} x$, es natural la conversión de la $\int$ en $x$, y no en $j$.

Los intentos académicos por ofrecer una explicación etimológica convincente de palabras de uso tan frecuente como caxas, caxones, xugo y dexaba, que así aparecen en la Aurora $(45,16,20,101)$, son fallidos en no pocos casos, como ha podido apreciarse. Por poner otro ejemplo más concreto, la Academia señaló que lejos había de escribirse con $j$ porque

18 Rosenblat (1971: 55) en su capítulo titulado precisamente “¿México o Méjico?” ilustra este conservadurismo con ejemplos que aparecen en nuestro corpus: "Pero los nombres propios son más conservadores que las voces corrientes. Y más que los nombres mismos, la letra de los nombres. El antiguo apellido Mexía (de Mesías) todavía lo usan algunas familias con $x$. Xérez se usó bastante en el siglo pasado". En cuanto al mantenimiento de esta grafía antigua en los topónimos, el mismo autor (57) recoge la opinión que al respecto manifestó Unamuno al sostener que no veía por qué México debía tener el privilegio de conservar una grafía (a la que llamó "equis intrusa”) que en otros muchos vocablos ya se había eliminado: “¿Ha de ser México más que Guadalaxara en esto? Sobre todo, igualdad ante la ley". 
provenía de longe, pero lo cierto es que procedía de laxus, de ahí que debiera haberse respetado la $x$ etimológica, como de hecho aparece en la Aurora (lexos, 3). Por todo ello, no es de extrañar que en el periódico chileno haya palabras que no se ajustan a su étimo latino, como ocurre con rexidor (188) y protejer, protexen $(85,36)$, y de que la duda de los redactores por la utilización de una u otra grafía se manifieste en la existencia de vacilaciones como xefe $(42,97)$ / gefe $(25,173)$, magestad $(58,143)$ / majestad $(144,146)$, baxo, rebaxas $(174,23)$ / bajo, vajo (175), o el caso de execución (155), que suele encontrarse escrito en el periódico chileno con $x$, aunque en ciertas ocasiones aparecen registradas las formas egecutiva y egecución $(6,187)$.

Por otra parte, es muy llamativa la abundancia de palabras con la terminación -age, quizás por una cierta influencia galicista; como préstamos del francés son las palabras libertinage (39), bagage (39), forragear (47), ultrage (48), mensage (63) homenage (92), equipages (152), paisanage (159) y espionage (177).

La confusión entre $b$ y $v$ procedía de la indistinción en la pronunciación de los sonidos bilabial oclusivo sonoro y del labiodental fricativo sonoro hacía ya tiempo, pues, como señalan Matus, Dargham y Samaniego (1992: 550): "en el reino de Chile, desde el momento de la conquista, se manifestó un solo fonema labial sonoro con representación vacilante". No obstante, no faltaron los que de forma escolar se empeñaron en mantener una diferenciación que ya era claramente artificial. Incluso el Autoridades optó por establecer las diferencias de pronunciación de $b$ y $v^{19}$ a pesar de ser consciente de su indistinción, como manifiesta ya en la introducción ${ }^{20}$. Más clara resulta la explicación que ofrece la Academia en su Orthographía $(1741$ ?: 123, 124) cuando señala la incapacidad de los hablantes para poder distinguir:

La $b$ confunde nuestra lengua con la $v$ consonante, porque en nuestra infancia no nos enseñaron a articular con distinta pronunciación la $v$ de la $b$. Dícese que la $b$ se pronuncia con los labios cerrados y la $v$ con los labios abiertos. Este especulativo precepto se dice muy bien y se entiende con facilidad, pero, llegando a la práctica, como no le empezamos a executar quando tiernas la lengua y la boca y expeditos sus músculos podíamos

19 Así, al hablar de la $b$ dice: "Tiene esta letra en nuestra lengua tan grande hermandad con la $v$ consonante en el modo de su pronunciación, que apenas las distingue el oído" (525), y al tratar de la $v$ : "Su pronunciación es casi como la de la $b$, aunque más blanda, para distinguirla de ella" (405).

20 "El uso de la $b$ y de la $v$ causa mucha confusión, nacida de que los españoles, como no hacemos distinción en la pronunciación de estas dos letras, igualmente nos hemos valido ya de la $b$, ya de la $v$, sin el menor reparo" (LXXII). 
jugar con facilidad de los labios ya endurecidos con la edad y difíciles los movimientos, nos es imposible practicar la obediencia.

Sin embargo, y a pesar del comentario anterior, durante mucho tiempo la institución académica siguió apoyando la existencia de los dos sonidos y criticando su indistinción, que achacaba a la incultura de los maestros ${ }^{21}$. Pero también fueron muchos los que en la enseñanza se esforzaban en inculcar a sus alumnos la diferente pronunciación. En este sentido, Bello, en sus "Advertencias sobre el uso de la lengua castellana dirigidas a los padres de familia, profesores de los colegios y maestros de escuela" (1833/1981: 862), insistirá en que:

los que se cuidan de evitar todo resabio de vulgarismo en su pronunciación (...) y si aspiran a una pronunciación más esmerada, distinguirán también la $s$ de la $z$ o la $c$, la $b$ de la $v$ y la $y$ consonante de la $i$ que forma diptongo con la vocal que se le sigue; de manera que suenen de diverso modo la casa que habitamos y la caza de los animales silvestres; la cima a que se sube y la sima a que se desciende; cabo, sustantivo, y cavo, verbo; el hierro, metal, y el yerro del entendimiento.

Esta preocupación en el ámbito escolar por diferenciar los sonidos $b / v$, como en el caso del seseo y del yeísmo, a fin de así evitar las faltas en la escritura, llega hasta no hace mucho tiempo, pues el propio Rodolfo Oroz (1966: 95) se percata de que, a pesar de que "esta pronunciación labiodental es prácticamente desconocida" en su época, "en numerosas escuelas primarias todavía se insiste -y siempre sin resultado- en enseñar la distinción entre $b$ y $v$ ".

La confusión de la $b$ y la $v$ es patente en la Aurora chilena, donde la aparición de bastantes formas que no se ajustan a la etimología ${ }^{22}$ son un claro indicio del carácter tradicionalista de un periódico que ha sido escrito en una zona alejada - en cierta medida- de los grandes núcleos editoriales,

21 De hecho, en la Ortografía de 1820 (51) afirmaba la Academia: "El confundir el sonido de la $b$ y de la $v$, como sucede comúnmente, es más negligencia o ignorancia de los maestros y preceptores, y culpa de la mala costumbre adquirida con los vicios y resabios de la educación doméstica y de las primeras escuelas, que naturaleza de sus voces; las cuales conocen y distinguen perfectamente los extranjeros que las pronuncian bien, y entre nosotros valencianos, catalanes y mallorquines, y algunos castellanos cultos que procuran hablar con propiedad su lengua nativa, corrigiendo los vicios vulgares o de la mala educación".

22 Formas como nuebo (1), esclabitud (1), soverano (2), serbir (14), save (14), atrebido (21), vandera (25), arrivaron (33), actibo (36), lebantar (39), todabía (49), jóbenes (81), cavezas (159). 
donde se apostaba por una ortografía humanística, más fiel al étimo. Muestra de ello es el verbo haber en todas sus formas, que se sigue escribiendo con $v$, aunque ya con la $h$ etimológica: haver, haviéndose, huvo $(18,3,4)$, si bien puede encontrarse la forma hubiésemos (19). Hay algunos imperfectos con - v- como iva (72) y obserbava (85), aunque son más frecuentes ya con $b$, como apoyaban (23), lograba (44), cultivaban (68), etc., y formas tan usuales como escrivir $(188)$ y govierno $(157,160)^{23}$. Esta indistinción gráfica también se da en antropónimos y topónimos tan extendidos como Estevan (24), Balero (24), Bentura (84), Talabera (56), La Havana (103), y en el gentilicio Cordovezes (156).

Nebrija se mostró muy innovador al señalar ya la necesidad de colocar $m$ ante $p$ y $b^{24}$, aunque no siempre se observe la correcta utilización de esta regla en sus propios escritos. El mantenimiento en la escritura de $n$ delante de las consonantes bilabiales oclusivas fue un rasgo de antiquísima tradición escrituraria que perduró incluso hasta el siglo XX, como bien muestra Frago Gracia (1998: 119) al recoger formas como inbocó o Canpos en manuscritos mejicanos todavía a mediados de esta centuria. En el periódico chileno se encuentran ejemplos de esta $n$ arcaizante en conbatida (23), desenpeño (32), honbre (67), inportancia (140), conbinación (182) y desmenbrado (183). Se registran, asimismo, lo que podrían considerarse faltas ortográficas pero que son, en realidad, muestras de la pervivencia del uso antiguo de $n$ ante b. Entre estos casos puede señalarse la aparición del grupo $m b$ en palabras que se escriben con $v$, como es el caso de imbariable (1p), desembuelve (1), embiadas (38), combalecencia (85), combeniente (85), palabras con $n v$ en lugar de mb en envarcaciones (14) y convates (24), y la colocación de la $m$ en formas como comvidados (3), septemtrional (15), imformados (18), comvencidos (31), imvocando (31), imferir (86) comvendrá y comvendría $(6,188)$.

23 Sin embargo, esta última voz se registra ya con $b$ en el pie de imprenta de todos los números.

24 "La $n$ nunca puede ponerse delante la $m, b, p$, antes, en los tales lugares, siempre avemos de poner $m$ en lugar de $n$, como en estas ediciones: ombre, emmudecer, emperador. Lo cual acontece por que donde se forma la $n$, que es hiriendo el pico de la lengua en la parte delantera del paladar, hasta donde se forman aquellas tres letras, ai tanta distancia, que fue forçado passarla en $m$, cuando alguna dellas se sigue, por estar tan cerca dellas en la pronunciación (Nebrija (1492) 1980: 132)". Sin embargo, Valdés ((c.1535) 2003:179), tan innovador en otros aspectos lingüísticos, opta en este caso por admitir las dos grafías: "M. ¿Qué parecer es el vuestro acerca del poner $m$ o $n$ antes de la $p$ y de la $b$ ? / V. Por mi fe, en esso tanto nunca seré muy supersticioso; bien sé que el latín quiere la $m$, y que a la verdad parece que sta bien, pero como no pronuncio sino $n$, huelgo ser descuidado en esto, y assí por complir con la una parte y con la otra, unas vezes escrivo $m$, y otras $n$ ". 
También de carácter arcaizante es la escritura de doble $r$ detrás de $n$ en formas como honrrar, honrradez, honrra (1p, 34, 61), Cabo Henrrique (3), enrriquezcan, enrriquecerla $(35,117)$, contrapunto de lo que sucede en concurentes, concurir $(19,75)$, prerogativa $(66,53,79)$, prorumpir $(75)$ y Virey (172), donde la vibrante múltiple aparece escrita con una $r$ simple. Frago Gracia (1998: 119) ya señaló la presencia de esta ere en formas como harimándole, ocurió o buro en manuscritos mexicanos de los siglos XVIII y XIX y en formas del tipo aborece y carera en el periódico bolivariano el Correo del Orinoco (2008: 40).

De sesgo marcadamente cultista es el mantenimiento de la $-h$ - etimológica en el infinitivo traher $(184,185)$ y en los verbos compuestos a partir de esta base: distraher (98), contraher (123, 162), atraher (126), extrahe (126), así como en otras formas verbales también con referencia etimologizante, cultismos gráficos pues: comprehende $(57,169)$, reprehendía $(155)$ y abhorrecen (74). Igualmente puede encontrarse la $h$ expletiva en palabras que, por ultracorrección gráfica, aparecen escritas con dicha letra a pesar de no poseerla en su étimo, como sucede con los verbos emprehender (125), sorprehender (87), habrirse (13, en 1813) y hera, imperfecto de ser (84), y vocablos como trahición (66) - o con seseo trahisión (70)-, acrehedor (142, 153), haliento (149) y cahos 'caos' (159). Esta preocupación cultista por evitar posibles errores contrasta con la abundancia de casos en los que no aparece la $h$ canónica, como en ablado (15), emisferio (22), arinas (172), eridas (158), orizonte (75) y la preposición acia $(1 \mathrm{p}, 3,43,146)^{25}$-por citar solo unos pocos-, e, incluso, en formas verbales en las que la incorrección ortográfica puede llevar a equívoco de no ser por el contexto que, en el ejemplo siguiente, indica que se trata del verbo echar y no del verbo hacer en una fórmula absoluta, como también parece indicar la tilde: "En este convite levantándose el Rey de su asiento hechó el siguiente brindis: «Mi hermano el Rey de la Gran Bretaña, (a cuya salud se havía bebido con tres veces tres) a lo qual añadió: «prospere y sea feliz contra Bonaparte...»" (4).

También se observa la falta de $h$ en el interior de palabras como exalan (67), reúse (192), exortación (175), adesión (83), y el trueque de la $h$ en alhagüeña (61), 'halagüeña'. En algunos casos, la duda del escritor es

25 La escritura de la preposición $\sin h$ es frecuente en este período, como constata Autoridades, que remite a la forma con $h$ y señala: "Esta voz se halla usada muchas veces $\sin$ la $h$; pero atendiendo a la etymología que la da Covarr. de la palabra $h a z$, y traherla con $h$ Nebrixa, el P. Salas y otros diccionarios, y hallarle del mismo modo en muchos autores clásicos antiguos, se debe escribir con ella". Esta forma $\sin h$ aparece hasta $1791 \mathrm{y}$ alude a la forma hacia, del mismo modo que Terreros. 
patente cuando en una misma página aparecen dos formas distintas, como ocurre con el extranjerismo úsares/húsares $(187)^{26}$. En otras ocasiones, la diferenciación no estaba clara ni siquiera en las obras de referencia, lo que sucede con hierro-yerro, que Bello proponía distinguir según su significado ${ }^{27}$, a diferencia de la Academia y Terreros ${ }^{28}$.

Todos estos casos de confusión se explican fácilmente si se tiene en cuenta que la $h$ ya era desde hacía siglos un signo meramente gráfico para quienes no aspiraban, mientras que era letra con referencia fonética para los aspiradores, aunque a comienzos del siglo XIX la aspiración había perdido mucho terreno y, sobre todo, su antiguo prestigio social. A este respecto, Oroz (1966: 123) observa la escasa existencia -frente a países como Argentina, Ecuador o México-de huellas de la $h$ aspirada en textos chilenos que reflejan el habla popular.

\section{FONÉTICA}

El estudio grafemático del texto es el medio más seguro para ahondar en el componente fonético, ya que en numerosas ocasiones la lengua oral deja su huella en la lengua escrita ${ }^{29}$. Como muestran sus páginas, el corpus periodístico chileno está elaborado con el afán de construir un discurso culto, aunque no deja por ello de contener algunas desviaciones que hoy podrían parecer vulgares y que son, en realidad, pequeñas muestras del apego a una tradición lingüística conservadora que se mantiene viva a pesar de los influjos innovadores procedentes de la corte virreinal de Lima, donde la influencia peninsular fue más directa.

26 La forma húsar aparece registrada en el DRAE por primera vez en 1803.

27 V. pág. $11(\mathrm{~b} / \mathrm{v})$.

28 Desde la edición de 1780 a 1791, la Academia recoge la entrada yerro con el significado: 'Por metal. V. hierro", al igual que Terreros, que, además de esta entrada, incluye la de hierro: 'error, falta, culpa, V. yerro'. En nuestro corpus aparece hierros con el significado de 'equivocaciones', como puede extraerse por el contexto: "Yo pido indulgencias para mis hierros, que jamás serán intencionales" (166). De este modo, tampoco parece extraño encontrar yele (67) en lugar de hiele.

29 No obstante, hay que ser cauteloso e insistir en la posibilidad de que ciertas modificaciones observadas en algunos términos se deban a meros errores de imprenta-creados, sin duda, por descuido en la escritura o bien en la composición gráfica-, y no a procesos fonéticos. 


\subsection{Vocalismo}

\subsubsection{Alteraciones en el vocalismo}

En el periódico chileno es evidente la existencia de ciertas desviaciones gráficas que pueden responder a meras erratas de imprenta ${ }^{30}, \mathrm{o}$ bien deberse a vacilaciones en el timbre vocálico provocadas por la inestabilidad de las vocales átonas, un fenómeno que "es causa de numerosas formas vacilantes que coexisten con las formas cultas estables" y "una de las características de los dialectos españoles" (Oroz 1966: 89). Del corpus periodístico pueden señalarse palabras como extraordenariamente (4), inseñanza (80), indespensables $(169)$, previlegio $(141,179)^{31}$, secritario $(72,88)$, crises 'crisis' (5, 111), enfelices (131), percebirán (141), indegencia (151), diliberar (155), deligencia (191) ${ }^{32}$. Entre estos ejemplos hay casos que, como señala Oroz (1966: 77), podrían explicarse por la acción de una nasal trabante sobre la vocal inacentuada que produciría el cambio de $i$ por $e$ en inseñanza, o bien el de $e$ por $i$ en formas como enfelices, vocablo este último que puede constituir un simple caso de dilación vocálica, o incluso puede deberse

${ }^{30}$ Como sin duda son los ejemplos siguientes: pantonosos (18), quedradas 'cuadradas'(49), eleboración (163), seministrarán (163), espicies (165), enquantra (53), Amírica (57), imprámase (152), verisimil (186).

En otras ocasiones puede apreciarse la eliminación de letras vocales en palabras como hermocer 'hermosear' (18), siguintes (25), septembre (61), Mediterrano (188), inutilzadas (91).

Además, aparecen en nuestros textos palabras con reduplicación de grafías vocales en términos como confiiscasión (150), hicieroon (91), fiin (111), baahía (138), o bien con la introducción de una vocal diferente quizás por contaminación con una vocal posterior: parrioquiales (136), lograisteis (182). El caso de auctual (18) podría deberse a una vocalización del grupo culto act, que Oroz $(1966: 141,142)$ ejemplifica a través del paso de acta $>$ áuta, acto $>$ auto. Suplientes (163) tampoco constituiría una errata de imprenta, pues es la forma que aparece en las ediciones académicas de 1803 y 1817, del mismo modo que desapiadada (158): en Autoridades aparece únicamente esta entrada y en ella explica su origen como "compuesto de la preposición des y la voz apiadado", mientras que Terrerros da cabida a desapiadado y despiadado, forma esta última que dice ser utilizada por Cervantes en la Casa de los Celos "por desapiadado". Estamos, por tanto, ante una forma arcaica que por primera vez remite a la forma moderna en 1925 y que aparece hasta el día de hoy en el DRAE sin la marca diacrónica "de poco uso" que le añadirán en la edición de 1983.

31 Tanto Terreros como Autoridades remiten a la forma actual privilegio (privilejio en el caso de Terreros). La Academia mantiene esta forma arcaica, previlegio, hasta su edición de 1803 .

32 Distinto caso supondría la forma crimines 'crímenes', hallada repetidas veces en el Manifiesto de Carrera (1818: 18, 35) -un latinismo nada extraño si se tiene en cuenta la exquisita formación que tuvo este político-, y que llega incluso a rastrearse en 1880 en los escritos del erudito español Marcelino Menéndez Pelayo (CORDE). 
a una causa de orden morfológico al tratarse, como ocurre también con indespensables, de formas derivadas.

Un caso distinto representan aquellas palabras que aparecen con su forma antigua: sostituto ${ }^{33}$, sostituirá $(17,36)$, e incluso otras que aún hoy pueden encontrarse en el diccionario académico: rigoroso ${ }^{34}$, rigorosamente $(94,38)$, deciembre $(63)^{35}$, sufocar $(118)^{36}$ y sus derivados sufocante y sufocadas (20, 126). Si no se consideran estas formas, propias de la época, se observa que los casos de posibles trueques en el timbre vocálico son muy pocos, si se tiene en cuenta la amplitud del corpus, lo que puede explicarse básicamente por el nivel cultural de los autores.

\subsubsection{Antihiatismo}

De filiación hispánica es el fenómeno del antihiatismo que aparece tempranamente en los textos americanos y que llegará a introducirse con el tiempo en el habla culta. En el periódico chileno puede encontrarse algún caso de simplificación del hiato ee $>e$ en términos como prover 'proveer' (58), cred 'creed' (2), crerían (96) y acredor (192), que coexisten con cultismos como comprehende, comprehendidos $(57,169,125)$. Como indica Oroz acerca del siglo XX, la reducción de esta doble vocal en una sola $e$ "es un fenómeno general de la lengua vulgar de Hispanoamérica; aparece en cualquier posición a lo largo de todo el país" y, curiosamente, incluye ejemplos como acredor y crer (1966: 70).

Así mismo, también puede señalarse en el texto chileno otra forma de antihiatismo, a saber, la conversión de un hiato en diptongo en los ejemplo deletéria, deletérios $(19 ; 18$, en 1813), contrapunto de lo que ocurre con la forma ultracorrecta Goatemala (138). Los ejemplos representativos de los dos tipos de antihiatismo hallados en la prensa chilena pueden considerarse

33 En el Manifiesto de Carrera (1818) aparecen también las formas sostituir, sostituirse $(25,27)$. Terreros y Autoridades incluyen esta entrada, aunque remiten a substituto. La Academia mantendrá esta forma hasta 1817, fecha en la que sustituto aparecerá ya como la forma estándar.

34 Terreros solo registra la forma actual riguroso, mientras que la Academia mantiene hasta hoy la forma con $o$ sin ni siquiera introducir marca diacrónica.

35 Terreros ni siquiera registra esta forma; por su parte, Autoridades remite a diciembre y añade: "Es formado del Latino December, por lo que parecía debía decirse Deciembre, pero el uso más común está en contrario". La Academia mantiene hasta hoy esta forma con la precisión de "desusada", a pesar de que ya en la edición de 1791 se calificaba de forma "antigua".

36 Terrero introduce sufocar y sofocar en una misma entrada, mientras que para Autoridades sufocar se trataba de la variante cultista preferida, una forma que hoy todavía tiene entrada en el $D R A E$ sin marcación temporal. 
todavía descuidos propios del habla vulgar, puesto que en la época, como señala Frago Gracia: "el modismo aún no debía de haber traspasado sino esporádicamente los límites del ámbito popular, pues raramente aparece en textos de autores cultivados o en el lenguaje formal" (2007: 159).

\subsection{Consonantismo}

\subsubsection{Grupos consonánticos}

La frecuente aparición en los textos de secuencias consonánticas simplificadas por pérdida del elemento implosivo es un claro indicio de que en la lengua oral tendían a no pronunciarse, fenómeno que llega hasta hoy. Sin embargo, la estimación social de esta reducción consonántica ha ido modificándose con el tiempo. Hasta el siglo XVIII fue una costumbre muy extendida sin ningún tipo de connotación negativa ${ }^{37}$, como, de hecho, señalaba Autoridades:

Aun entre los más preciados de verdaderos y legítimos castellanos tampoco hai igualdad en el modo de pronunciar, porque lo que unos profieren con toda expressión, diciendo acepto, lección, lector, doctrina, propriedad, satisfacción, doctor, otros pronuncian con blandura y dicen aceto, leción, letor, dotrina, propiedad, satisfación, dotor (LXVII, LXVIII).

No resulta extraño, pues, que la Academia, al percatarse de esta diversidad de tratamientos de los grupos cultos, se viera en la obligación de regularizar su escritura, para lo que adoptaría como regla básica la etimología ${ }^{38}$; paulatinamente se irá asentando en la conciencia lingüística del escritor la necesidad de respetar estos grupos, de tal modo que a principios del siglo XIX

37 En este sentido, Frago Gracia (2002: 429) aporta los ejemplos de grandes escritores como Juan del Encina y Juan de Valdés, que preferían las formas dino, defeto..., frente a otros como Torres Naharro que se decantaban por la conservación del grupo consonántico, lo que en poesía venía motivado también por exigencias de la rima.

38 Sin embargo, los criterios que adoptó en este punto la Academia han sido vacilantes a lo largo de su historia, como señala Rosenblat (1971: 44): "A través de las diez y ocho ediciones de su Diccionario y de las repetidas ediciones de su Ortografía (incorporada luego a la Gramática), ha ido acomodándose a las oscilaciones de la lengua culta. Y hoy alternan, en el Diccionario, setiembre y septiembre, oscuro y obscuro...". Al respecto, este autor recoge una anécdota curiosa de Unamuno: "En uno de sus artículos había escrito oscuro. El regente de la imprenta, al enviarle las galeradas, le puso al margen -como era tradición en las buenas imprentas españolas- una llamada: "Ojo: obscuro." Unamuno contestó: "Oído: oscuro"” (45). 
la simplificación ya podía considerarse un rasgo de carácter vulgar ${ }^{39}$. Hoy, la articulación relajada de las consonantes en posición silábica implosiva todavía se manifiesta frecuentemente en la reducción consonántica, con diferente consideración social, dependiendo del país. Al respecto, Oroz (1966: 127) señala cómo “[en Chile] la reducción de las consonantes dobles a una sola no se limita, como en casi todas partes, al habla popular, sino que se da también en el habla culta"; no obstante, añade, también es importante tener en cuenta qué tipo de agrupación consonántica se simplifica, pues al tratar de cada uno de los grupos este estudioso establece diferencias según el tipo de instrucción recibida ${ }^{40}$.

En el corpus periodístico chileno se puede hallar todavía una cantidad de reducciones consonánticas nada despreciable. Aparecen casos como obiar 'obviar', ovio, obios $(5,66,60)$, simplificación de $c c$ en formas como produciones, direción y correción $(18,171 ; 14$, en 1813), del grupo $c t>t$ en los vocablos infrutuoso, frutuosa $(147 ; 15$, en 1813), o de $n s$ en incostancia e incostante $(66,147)$. Más frecuente es la alteración gráfica del grupo cuando éste está compuesto por dos elementos nasales, generalmente por asimilación de $/ \mathrm{n} /$ a la $/ \mathrm{m} /$ siguiente, como muestran formas como immoral (16), immundas (18), immediato (25), commociones (56), immensa (63), immortales (66), emmudecieron (90), también por simplificación del grupo, como en imensa $(56,78)$, en la reducción de $n n$ en inumerables $(179,190)$, o de $m n$ en calunia $(169)^{41}$. Estos ejemplos ponen de manifiesto la innegable vacilación que en la escritura había de los grupos consonánticos, por lo que no es de extrañar que la conciencia lingüística del hablante interviniera activamente en su reproducción escrita para evitar formas populares, a lo que obedece, sin duda, la aparición de la ultracorrección gráfica en demostracción (56), palabra que en el Manifiesto de Carrera aparece con el grupo cultista conservado: demonstraciones $(24,30)^{42}$.

39 A la luz de documentación de distinta época, Matus, Dargham y Samaniego (1992: 552) reflejan perfectamente la evolución de este fenómeno: "Sin embargo, mientras en el siglo XVI son escasas las formas con grupos cultos, en el siglo XVII se hacen frecuentes y muy abundantes en el XVIII, por lo que este siglo aparece marcado por la tendencia normalizadora a restituirlos. La tradición simplificadora quedaría relegada a los niveles socioculturales inferiores, puesto que ella tiene gran arraigo, en tales estratos hasta hoy (Oroz 1966: 141 ss.)".

40 De este modo, señala por ejemplo: "En el grupo ortográfico -cc-, las personas instruidas pronuncian ks: acción aksjo'n” (122).

${ }_{41} \mathrm{Al}$ respecto, Oroz explica cómo "en la clase media hay una leve relajación de la $n$ en: conmigo", mientras que "la lengua popular usa comigo; imortal por inmortal" (1966: 109).

42 También se halla en el texto chileno occéano con doble $c(55,56)$, forma que fue frecuente en los siglos XVII y XVIII, como pone de manifiesto el Autoridades: "[Océano] viene del latino Oceanus, por cuya razón debe escribirse con una sola $c$, aunque los más la duplican”. 
Por otra parte, en el periódico chileno se constata también el mantenimiento, por un afán meramente cultista, del grupo consonántico que ciertos vocablos poseían en latín en casos como commodidades o la forma ligeramente alterada conmodamente $(78,81)$, occupaciones $(53)$, objecto $(18)$, punctual (191), extincción (57), las formas succesivamente, succeden, succesión $(155,161,138)$, en alternancia con subcedían, subcesivo, subcesión $(5,7,31)$, o bien las siguientes: constumbre (2), constumbres $(1,2$ veces) y aconstumbrados (1), lo más probablemente latinismos, sin que radicalmente pueda descartarse la dilación regresiva de la nasal siguiente ${ }^{43}$.

La inclinación a la pérdida del elemento implosivo del grupo $/ \mathrm{ks} /$ en cultismos es uno de los rasgos más frecuentes de la pronunciación hispánica desde antiguo, preferentemente cuando esta secuencia fónica estaba ante consonante (en casos como extraer o extender). De hecho, la Academia tardó en fijar la escritura de este grupo con $x$, como pone de manifiesto la novena edición (1820: 55, 56), en donde puede leerse todavía: "Por el fácil tránsito y conmutación de la $x$ a la $s$ podrá esta sustituirse a la primera cuando la sigue una consonante como en estrangero, estraño, estremo, ya para hacer más dulce y suave la pronunciación, ya para evitar cierta afectación con que se pronuncie en esos casos la $x " 44$. Oroz (1966: 122) ofrece el testimonio más reciente de la pronunciación de este grupo, según si va sucedido por una consonante o una vocal. Así, mientras que la $x$ "ante consonante se pronuncia, en el habla común, igual que en España, como una simple $s$ : exposición [esposisjón] o [e $\mathrm{e}^{\mathrm{h}}$ posisjón]; extraño [estráno] o [e tráno]”, entre vocales se pronuncia "a menudo como $\gamma \mathrm{s}$ : examen eүsámen (Chiloé, etc.); pero en la lengua culta, en general, como ks: eksámen".

No es extraño, de este modo, que en el corpus chileno la relajación de este grupo deje su huella en formas como estremidades (1p), estrangeros (2p), estenso (14), esteriores (39), pretesto (48), estravagancia (77), espusieron

43 Estas formas proceden de los siguientes vocablos latinos: cómodo $<$ cŏmmŏdus, ocupar $<$ occŭpare, objeto < objectum, punto < pŭnctum, extinción $<$ exstincť̈o, suceder $<$ succedere, costumbre $<$ consuêtūdo. A excepción de extincción-que solo está registrado en un documento de B. L. de Argensola, quizás por obedecer a una variación del étimo-, todas ellas son formas que aparecen frecuentemente registradas en el CORDE en documentos antiguos y también en obras del XVIII.

44 Rosenblat (1971: 51) rastrea las normas de escritura de $s$ o $x$ para grafiar el grupo $/ \mathrm{ks} /$ y señala: "Las dos grafías ( $x$ y $s$ ) alternaron en los textos académicos hasta que el Prontuario ortográfico de 1844, y luego la Gramática de 1864, que incluye por primera vez la Ortografía, reaccionó contra la $s "$. 
(83), misto (140) ${ }^{45}$, “a espensas" (153), estraño (161), espuestos (148), esperimenta (174), incluso en el topónimo Estremadura (38; 2 en 1813) $\mathrm{y}$ el correspondiente gentilicio estremeños $(63)^{46}$. A veces, en un mismo párrafo el redactor puede introducir la forma correcta y la vulgar, lo que se puede comprobar con las formas extiende y estensión (49); otras veces, se encuentran casos en los que se mantiene el grupo $/ \mathrm{ks} / \mathrm{y}$ se le añade una $s$, como en exsecración (121) y exsista (14), ultracorrecciones influidas por el fenómeno seseoso, así como la hipercorrección reflecciva 'reflexiva' (2), con resultado gráficamente ceceoso.

El esfuerzo que hacen los redactores para evitar la simplificación de $x$ en $s$ les hace caer en otras ultracorrecciones, lo que se evidencia en formas como exfuerzo (22), extragos $(55 ; 18$, en 1813), protexta (61), expontáneamente (65), explendor (79), extructura (93), así como las grafías recurrentes contextó, contexta, contextación e incontextablememente (41, 61, 96, 169), o el caso de detextan en la proclama de O'Higgins (1818). En otros casos, no se trata de ultracorrección, sino simplemente de mantenimiento de la $x$ cultista: dextreza (175) y anxiedad (56) ${ }^{47}$.

\subsection{2. /-s/ implosiva}

La aspiración de /-s/ implosiva a final de sílaba o palabra es un fenómeno muy extendido en el español americano, si bien "alcanza mayor grado en Chile junto a la Argentina, Venezuela y las Antillas", como señala Oroz (1966: 101). No obstante, la pronunciación del sonido implosivo puede fluctuar desde la articulación plena hasta su completa desaparición, dependiendo de la instrucción del hablante, así como de la situación comunicativa. En este sentido, el investigador chileno explica cómo "en Chile, la $s$ final de sílaba

45 La forma misto aparece registrada en el DRAE desde 1817 hasta hoy (con la marca de "poco usado"). Es a partir de la edición de 1869 cuando remite a mixto.

46 La misma Academia mezclaba criterios a la hora de seleccionar sus entradas: "Al reimprimir el primer volumen de su Diccionario de Autoridades, en 1770, admitió estraño, Estremadura, escusado, estrangero, etc., pero también explicación, expresión, expresivas, etc" (Rosenblat 1971: 50).

47 Destreza procede de diestro < děxter (con $x$ lo registra el CORDE en documentos del s. XVI). Más controversia plantea el vocablo ansiedad, del que no se puede saber si la grafía $x$ se toma del latín, pues Corominas (1954) señala que, "como es poco frecuente antes de la $2^{\mathrm{a}}$ mitad del s. XIX, es posible que más que del latín anxiětas, venga del francés anxiété", y añade: "hoy se lee mucho en el sentido de 'anhelo', por anglicismo, en la prensa hispanoamericana". En el DRAE, curiosamente, la forma anxiedad aparece registrada una sola vez en la edición de 1933 con el marcador de "antigua", y lo cierto es que en el CORDE aparecen registros de esta forma en documentos de los siglos XV y XVI. 
es comúnmente semiaspirada, en el habla culta, y del todo aspirada o muda, en la lengua popular" (1966: 105).

Más difícil resulta discernir la aparición de este fenómeno en documentos chilenos de siglos pasados debido al prurito cultista del que hacían gala los escritores, sobre todo en cierto tipo de textos. En este sentido, Matus, Dargham y Samaniego (1992: 551) señalan la escasez de casos en los que la aspiración y pérdida de ese implosiva es perceptible en su documentación, y concluyen diciendo: "En el siglo XVIII debió arraigar poderosamente en el habla de todos los niveles sociolingüísticos, única forma de explicar el total arraigo del fenómeno en textos dialectales del siglo XIX".

En el periódico chileno, la relajación y pérdida de la $/-S /$ implosiva aparece, por ejemplo, en palabras que poseen el segmento fónico inicial discomo en dipuestos $(109)^{48}$, así como cuando la ese implosiva va precediendo a una consonante oclusiva sorda, salvo en el caso de degracias (158), en formas como reconquitar (1), repetos (148), retablecer (149), funetas (156), conquitadores (144), indutria (163). También se dan casos de pérdida de $s$ ante una labial fricativa en efuerzos (148), eforsaba (149), o en el ejemplo curioso de la expresión "al blafemo!" (142). Un caso de ultracorrección gráfica podría ser la forma desmuestran (161), aunque quizás también pudiera deberse a un falso análisis de prefijo (des), o simplemente tratarse de una mera errata.

\subsubsection{Otros fenómenos consonánticos}

En la Aurora chilena se hallan las formas morimundos (120) y muchedumdre (125), que pueden explicarse por asimilación con sonidos próximos, sin descartar la simple errata ${ }^{49}$. De un caso diferente se trata la

48 Distinto es el caso de diminución $(10,59)$, forma frecuente en la época. De hecho, Autoridades en la entrada disminución remite a diminución, y en la forma verbal disminuir (lat. diminuěre) señala: "Algunos dicen desminuir y otros diminuir".

49 De otra parte, la forma estatística 'estadística' (151) puede deberse, como señala Corominas (1954), a la adaptación del francés statistique, pues la forma actual entra en el DRAE en la edición de 1822. Fueron muchos los vocablos técnicos que en esa época penetraron en la lengua procedentes del inglés y el francés, sobre todo, de ahí que aparezcan en estas fechas formas todavía no adaptadas a la fonética hispánica, como la anterior o commodoro (del inglés commodore, que a su vez viene del francés commandeur 'comandante'), que aparece en el Manifiesto de Carrera $(12,32)$. Por otra parte, es destacable también la aparición en nuestro texto de produsga (20), forma verbal de reminiscencia tradicional que registra el CORDE en un escritor del XVII. Matus, Dargham y Samaniego (1992: 553) explican que hubo "conjugaciones de verbos que tardaron más en fijarse", y señalan precisamente la forma reprodusgo, que hallan en el criollo Vicente Martínez Yupangui, en un documento de 1726. 
forma constituentes 'constituyentes' (72, 146, 2 veces), donde la desaparición del elemento palatal $/ \mathrm{y} /$ puede deberse a su contacto con la vocal del mismo orden articulatorio. Por otra parte, más restringido al ámbito meridional $\mathrm{y}$, por extensión, a los territorios americanos, es la neutralización de /-r/, /-1/, fenómeno marcadamente popular del que no se ha encontrado representación en el texto chileno ${ }^{50}$. Sin embargo, la distensión articulatoria de la consonante líquida propicia su desaparición en el caso de inmotales (141). Como fenómeno próximo a la neutralización y eliminación de líquidas puede señalarse la sustitución de la $d$ por $l, r$ ante labial, fenómeno que en ciertas voces $\operatorname{Oroz}(1966: 172,173)$ explica por confusión de ad-con el prefijo al-y señala, entre otros, ejemplos como alvertir o arvierto $^{51}$. En nuestro caso, se registran las siguientes confusiones con $r$ : arversión (128) y arvertir (148), así como la forma adbitrio ( 83,2 veces), único testimonio de la confusión de /r/ y /1/ implosivas que Matus, Dargham y Samaniego (1992: 550, 551) hallan en su corpus, lo que explican por "la irradiación normalizadora de Lima para Chile y el área de Tucumán"; esto no significa que el fenómeno no se diera, sino que quedó "relegado a los niveles inferiores donde, sin duda, arraigó y tiene tenacidad histórica hasta hoy" ${ }^{2}$.

\subsubsection{Yeísmo}

De gran concisión es la afirmación de Oroz (1966: 197): "El yeísmo y el seseo son, en el fondo, los únicos hechos fonológicos de consideración,

50 Oroz (1966: 158) señala que "hay tendencia a disimilación de -al $>-a r$, cuando precede otra $l$ : delantar (centro y sur)". Por ello, podría parecer que la forma elementar (82, 2 veces, 191) y su plural elementares (80), que aparece en la Aurora, se deben a un fenómeno de neutralización de líquidas. Sin embargo, esta forma, procedente de una $r$ latina (ělěmentārǔus), fue considerada de uso normal hasta el siglo XX y aún hoy se puede encontrar en el $D R A E$ con la marcación "adjetivo desusado".

51 Oroz (1966: 172, 173) observa que "en todo el sur hasta Talca prevalecen, en general, las formas con al-(alverbio)", mientras que "de Talca al norte, las con ar- (arvertir)". Esta diferenciación diatópica es paralela a la que páginas antes había resaltado al hablar de la neutralización de las líquidas: "Se puede decir que la igualación de $l$ y $r$ finales de sílaba bajo el sonido predominante de la primera: colpiño, caltón, etc., es característica del sur, centro meridional y centro; en cambio, la uniformación bajo la forma fonética de la $r$ alcanza desde Puerto Montt hasta Antofagasta: durce, barde, etc" (170).

52 El trueque ocasional de líquidas puede observarse también en el periódico chileno en la forma celebro (162), vocablo que Oroz (1966: 156, 157) incluye entre los casos de disimilación consonántica de aparición frecuente en la lengua popular de todo el país, si bien se trata de un puro arcaísmo lexicalizado que llega hasta hoy (en el $D R A E$ aparece como "desusado"), y que fue de uso extendido en la época, como muestra el Autoridades: "[celebro] viene del latino cerebrum, por cuya razón se dice también cerebro, aunque se usa menos". 
por los cuales se diferencia el español de Chile del de la península". Sin embargo, hay que precisar bastante esta cita en varios puntos. En primer lugar, porque las diferencias son tanto o más notables a ambos lados del océano en cuanto a las pronunciaciones de la velar $/ \mathrm{h} /$, más palatales en algunas zonas americanas y sobre todo en Chile. Por otra parte, porque el seseo está presente en ciertas hablas peninsulares, del mismo modo que el fenómeno del yeísmo, que se ha extendido casi de forma general por todo el territorio español en un proceso que se ha intensificado en las últimas décadas. Oroz se percató de la extensión de este fenómeno en Chile, y en los años 60 escribía (1966: 119-120): "En resumen, puede decirse que casi todo Chile es hoy día zona del yeísmo; las reducidas áreas del lleísmo que aún subsisten, están, sin duda, condenadas a desaparecer, y el uso de $l l$ fuera de esas regiones se considera como cursilería", y apunta más adelante: "La situación relativa a este problema ha variado sólo en los últimos cincuenta años".

En la Aurora chilena no se halla ningún caso de yeísmo o lleísmo gráfico, un dato que en absoluto puede ser determinante para caracterizar la pronunciación de los redactores del periódico; esta ausencia de errores gráficos puede deberse simplemente al cuidado con el que escritores y editores redactaron el periódico. Lo cierto es que el yeísmo fónico existía, como ponen de manifiesto textos redactados por gente perteneciente a una clase social menos instruida, como explican Matus, Dargham y Samaniego (1992: 550):

En los documentos analizados no se manifiesta ninguna confusión que implique neutralización de estos fonemas. La única explicación radica en el nivel sociocultural de los autores, puesto que el fenómeno está ampliamente atestiguado, en el siglo XVI, en España y en América, en documentos de bajo estrato. Si tomamos en cuenta que está fuertemente arraigado en textos dialectales del siglo XIX (Matus 1990), hay que suponer que tendría amplia difusión en el XVIII, sólo que la confusión (yeísmo) estaría estigmatizada socialmente y sólo ocurriría en los niveles sociolingüísticos inferiores.

\subsubsection{Seseo}

Son numerosísimos los deslices seseo-ceceosos esparcidos a lo largo del periódico chileno, no solo en proclamas sino también en noticias y comunicados oficiales. Esto es debido a diversas causas, entre ellas y dicho de forma sucinta: la existencia de muchísimas más palabras que llevan $s, c$, $z$ que las que llevan $y$ o $l l$, la dificultad que entraña para un hablante seseoso el manejo de tres letras para representar un solo sonido, así como la pronta 
identificación de los criollos con esa pronunciación, idea que desarrolló Frago Gracia hace ya algunos años y que viene apoyada por más datos documentales en su obra reciente (2010: 300-301), donde concluye:

Semejante proliferación de la grafía seseosa no se verifica en los manuscritos andaluces coetáneos de nivel cultural medio y alto, lo que desde hace años me ha llevado a pensar que muchos criollos habían tomado conciencia de su seseo y se habían identificado culturalmente con él, desde el momento en que la barrera levantada por la cultura ortográfica en la formación escolar y por las lecturas no impedía la continua afloración de su modismo fonético en la escritura: sin duda por ello el cometer seseo gráfico les resultaba indiferente, y quizá hasta natural.

En la Aurora chilena se observa, por ejemplo, que ya en el prospecto, firmado por Camilo Henríquez, aparecen las siguientes alteraciones de $c$ por $s$ : dicipar (1), concideración (2), iglecia (2), ecleciástico (2), converción (2), obuces (2) y fuciles (2), aunque son más numerosos los casos de $s$ por c: presioso (1), conosimiento (1), esfuersos (también esfuerzos en esa misma página, 1), nascan (2), desente (2), dies (2), organisación (2), serrado (2), dulses (3), almasén (3) y dose (en alternancia con doce, 3), tendencia observable a lo largo de todo el periódico, si bien en algún que otro ejemplar los trueques de $c$ por $s$ son mayores en número que los de $s$ por $c$, como ocurre con el cuarto número, por ejemplo, en el que aparecen los siguientes casos: de un lado, utencilios (17), desaceo (hasta en seis ocasiones y nunca registrado con $s$, 18), estención (18), náucea (18), aceo (18), obcervación (18), hermocer 'hermosear' (18), iglecia (19) y gaz/es (con numerosos testimonios, 19) y, de otro lado, casos como apresiables (18) enserrada, enserrar (19) y conosca (20). Estos deslices gráficos seseo-ceceosos son tan abundantes que aparecen incluso en antropónimos y topónimos, nombres propios cuya corrección ortográfica parece que ha de ser mayor al tratarse de elementos léxicos ya de asentamiento tradicional: Ximénes (45), Ysquierdo (45), Días (62), Álvares (74), Narsiso (76), Senteno (76), Indalesio (106), Baltazar (163), Velásques (136), Suáres (152), Dionicio (184), Gusmán (191); la incorrección ortográfica aparece incluso doblada en la expresión de nombre y cargo: "Cristoval de Mendosa Precidente pro tempore" (31). Son menos frecuentes los casos de topónimos del tipo Algesiras (33), Zegura (103) y Escosia (149), aunque algunos son tan usuales como Brazil (150) y Viscaya o Nueva Vicaya $(60,122)$.

Así mismo, el seseo motiva la reducción de la secuencia gráfica - $x c-\mathrm{y}$ las dudas del redactor de prensa se hacen patentes en la vacilación de formas que aparecen incluso en el mismo folio, como es el caso de Exelentísimo (61, 62, 2 veces) / Excelentísimo (61) o Exelentísima (61) / Excelentísima 
(62). Diversos son los tratamientos que recibe este grupo cuando va seguido de $c$; se observa el mantenimiento de la $x$ en la mayoría de los casos, en las palabras exesos $(147,154)$, exitar 'excitar', exitarán, exitándolos $(147,46$, 136), exelente, exelencia, exelentísimo, Exelentísima $(67,54,190,45)^{53}$. Más rara es la simplificación del grupo $/ \mathrm{ks} /$ a través de la eliminación de la grafía $x$ en los casos eceptuado y eceptuadas $(48,181)$.

Otro grupo grafémico que suele aparecer simplificado debido al fenómeno seseoso es - $s c$ - seguido de $e, i$, con una solución que manifiesta, en la mayoría de las ocasiones, la desaparición de la letra $s$, como se puede ver en los siguientes casos: diciplina, diciplinan, diciplinada (71, 107, 166), dicernimiento (120), efervecencia, eferbecencia (101), facinar (150), dicípulos $(10$, en 1813), en los numerales trecientos, trecientas $(32,122)$ y docientos, docientas $(32,49)$, en las formas del verbo ascender: aciende, acienden, acendían, acendido $(54,127,106,67)$, y en las de su antónimo descender: deciende, decendamos, decendemos decendi, decendencia, decendientes $(143,122,77,123,144,166)$. Mucho menos frecuente es la desaparición de la $c$ como ocurre con esena 'escena' (84) o impresindibles (162), lo que quizás pueda deberse al prurito lingüista de los impresores. En cualquier caso, la vacilación es siempre manifiesta, como se observa con dobletes del tipo suseptible (2) / suceptible $(55,65)$.

\section{A MODO DE CONCLUSIÓN}

La aparición del celebrado periódico independentista la Aurora de Chile marca un hito de indudable importancia en la historia cultural de una nación que hasta esa fecha carecía de una imprenta propia $^{54}$, frente a países como

53 La forma exelente, muy frecuente en la Aurora $(67,68,70,136,153,183)$, aparece también en el Manifiesto de Carrera (4) junto a formas como exitaba, exitaron $(9,16)$.

54 El historiador Medina Zavala $(1958: 304,305)$ explica los inicios de la imprenta chilena de la mano de José Camilo Gallardo, que estableció su pequeño taller en la Universidad de San Felipe (en torno a 1800). Y añade: "es indudable que Gallardo trabajó en la imprenta de la Aurora al lado de los tipógrafos americanos que tenían a su cargo la impresión del periódico", dato que justifica con el anuncio extraído de la Aurora de Chile, del número 4, fechado en 28 de enero de 1813 (16), que dice así: "Se vende con equidad un coche forrado en terciopelo de seda, charolado y colgado a la moda, con ladillos de cristal y también de madera. Quien quisiere comprarlo y las guarniciones para el tiro, ocurra a Dn. Josef Camilo Gallardo en la Oficina de la Imprenta". 
México o Perú, que contaban con una gran tradición editorial. Y de todos es sabido que la existencia de la tipografía es uno de los mayores potenciadores de la normalización ortográfica, de ahí que no sea de extrañar el hecho de que la letra de molde del periódico chileno presente todavía un gran apego a los tradicionales usos gráficos de la escritura manual, como se ha visto a la luz de formas con doble $r$ detrás de $n$ en honrrar, la aparición de formas como gerra 'guerra' o urguían 'urgían', o el mantenimiento de la $n$ delante de las bilabiales oclusivas en casos como conbatida, por poner solo algunos ejemplos.

Pero, además de la carencia de una tradición impresa consolidada en Chile, es necesario considerar otros aspectos ya de carácter más general para la época. Así, cuando se analiza la ortografía del periódico chileno, o de cualquier otro impreso hispanoamericano o peninsular, se observa la aparición de vacilaciones ortográficas del tipo xefe/gefe, haver/haber que ponen de manifiesto la inexistencia de unas reglas claramente fijadas, y no es algo sorprendente si se tiene en cuenta que no había unidad ortográfica ni siquiera en la metrópoli, pues las pautas ortográficas que fijaba la Real Academia Española tardaron en imponerse en España, incluso entre los mismos académicos, que a cada paso se contradecían en su obra, lo que se pone de manifiesto en los desajustes existentes entre las explicaciones fonéticas que aportan y las reglas que formulan, como en el caso de $b / v$, por no hablar de las veces en las que se enuncian normas que no se adoptan de forma regular en los textos académicos, como ocurre con la $q$ latinizante, que fue eliminada en 1775 y que, no obstante, seguirá apareciendo en entradas del diccionario como qual, qualidad, adequado hasta la edición de 1803.

Quizás sea una generalización demasiado simplista caracterizar la Aurora chilena como un texto cuidado formalmente, si se tiene en cuenta que se trata de un corpus muy amplio, en el que hay noticias, anuncios, proclamas, manifiestos, etc., aunque lo cierto es que la tónica general es la existencia de mayor uniformidad ortográfica cuando se presentan informaciones relativas al gobierno. Además, se trata de un periódico en el que se introducen a cada paso noticias procedentes de otros países hispanohablantes -copiadas en parte o íntegramente de otros periódicos-, así como de fragmentos traducidos de otras lenguas. Se plantean, de este modo, problemas relacionados con la heterogeneidad de los materiales, así como dificultades añadidas provenientes del proceso de traducción y de las posibles interferencias del castellano con la lengua origen, cuyas huellas, no obstante, son más significativas en los planos de la gramática y del léxico, donde aparecen calcos evidentes del francés y del inglés, sobre todo.

No obstante, el análisis ortográfico y fonético de las páginas del corpus periodístico chileno revela la buena formación escolar de los redactores 
del periódico, así como una cierta conciencia lingüística que en ocasiones les lleva a cometer ultracorrecciones del tipo de exfuerzo, conscientes de que la relajación del grupo $/ \mathrm{ks} /$ en la pronunciación les confundía a la hora de escribir, como ciertamente sucedía y queda reflejado en formas como estrangeros o estraño. De cualquier modo, evidente es el afán de los escritores por elaborar textos con un estilo elevado y grandilocuente, en aras de construir un discurso atrayente que lograra captar la atención del lector, no solo con miras económicas, sino ante todo con el objetivo primordial de conseguir adhesiones ideológicas a la causa independentista en un momento en el que la retórica tenía un gran valor. 


\section{REFERENCIAS BIBLIOGRÁFICAS}

Aurora de ChILE. 1812-1813. [en línea]. Disponible en http://www.auroradechile.cl/ newtenberg/681/propertyname-699.html. [Consulta 11/12/2009].

Bello, AndRÉs. (1833) 1981. Advertencias sobre el uso de la lengua castellana dirigidas a los padres de familia, profesores de los colegios y maestros de escuela. Antología General de Andrés Bello. Tomo I. Madrid: Editorial Mediterráneo, pp. 846-873.

Carrera, José Miguel de. 1818. Manifiesto que hace a los pueblos de Chile [en línea]. Disponible en http: //www.memoriachilena.cl/temas/documento_detalle.asp?id= MC0009048 [Consulta 11/12/2009].

Covarrubias Orozco, Sebastí́n de. (1611) 1979. Tesoro de la lengua castellana o española. Madrid: Turner.

Corominas, Joan. 1954. Diccionario crítico etimológico de la lengua castellana. Madrid: Gredos.

DiCCIONARIO DE AUtORIDADES. (1726-1739) 1969. Madrid: Gredos.

Frago Gracia, Juan Antonio. 1993. Historia de las hablas andaluzas. Madrid: Arco Libros.

1998. Tradición e innovación ortográfica en manuscritos mexicanos: implicaciones culturales y lingüísticas en el hecho textual. En José Manuel Blecua, Juan Gutiérrez y Lidia Salas (eds.). Estudios de grafemática en el dominio hispánico, Salamanca: Ediciones Universidad de Salamanca e Instituto Caro y Cuervo, pp. 97-121.

2002. Textos y normas. Comentarios lingüísticos. Madrid: Gredos.

2007. Tradición e innovación en el español americano de la independencia. Romance Philology 61: 147-191.

2008. Conciencia lingüística del criollo en la independencia. Hablar castellanocolombiano. Boletín de la Real Academia Española, Tomo LXXXVIII, Cuaderno CCXVII: 34-76.

Taurus.

HeRnÁNDEZ Alonso, CÉSAR (coor.) 1992. Historia y presente del español de América. Valladolid: Junta de Castilla y León, Pabecal.

Matus, Alfredo, Soledad Dargham y José Luis Samaniego. 1992. Notas para una historia del español en Chile. En César Hernández Alonso (coord.). Historia y presente del español de América. Valladolid: Junta de Castilla y León, Pabecal, pp. 543-564.

Medina Zavala, José Toribio (1958). Historia de la imprenta en los antiguos dominios españoles de América y Oceanía. Tomo II. Santiago de Chile: Fondo histórico y bibliográfico José Toribio Medina. 
Nebrija, Antonio DE. (1492) 1980. Gramática de la lengua castellana, Antonio Quilis (ed.). Madrid: Editora Nacional.

O'Higgins, Bernardo. 1818. Al ejército de Lima [en línea]. Disponible en http://www. memoriachilena.cl//temas/documento_detalle.asp?id=MC0008858

[Consulta 9/12/2009].

Oroz, Rodolfo. 1966. La lengua castellana en Chile. Santiago: Facultad de Filosofía y Educación, Universidad de Chile.

Real Academia Española. Banco de datos (CORDE). Corpus diacrónico del español [en línea]. Disponible en http://www.rae.es. [Consulta 11/12/2009].

- Nuevo Tesoro Lexicográfico de la Lengua Española (NTLLE) [en línea]. Disponible en http://buscon.rae.es/ntlle/SrvltGUILoginNtlle. [Consulta 11/12/2009].

- 1820. ( $9^{a}$ ed.). Ortografía. Madrid: Imprenta Nacional. [en línea]. Disponible en http://www.archive.org/stream/ortografadelale01espagoog\# page/n11/mode/1up [Consulta 10/01/2010].

1741? Orthographía española. [en línea]. Disponible en http://www. cervantesvirtual.com/servlet/SirveObras/01159630108920410760035/thm0000.htm. [Consulta 11/12/2009].

Rosenblat, Ángel. 1971. Fetichismo de la letra. Nuestra lengua en ambos mundos, Barcelona: Salvat Editores, pp. 41-81.

Terreros y Pando, Esteban De. (1786-1793) 1987. Diccionario castellano con las voces de ciencias y artes. Madrid: Arco Libros.

VAldés, Juan DE. (c.1535) 2003. Diálogo de la lengua. Cristina Barbolani (ed.). Madrid: Cátedra. 